\title{
Pleural effusion in silicosis of the lung
}

\author{
Feisal A Al-Kassimi
}

I report pleural effusion in a patient with silicosis of the lung and pulmonary massive fibrosis. No specific aetiology for the effusion was detected after thorough investigation and a long follow up period. I speculate that, similar to asbestosis, ${ }^{12}$ silicosis of the lung might produce a benign pleural effusion. There are similarities in the inflammatory and exudative tissue response to both types of dust particles. ${ }^{3-5}$

I am not aware of any previous reports of association between silicosis of the lung and pleural effusion.

\section{Case report}

A man of 70 presented with a 30 year history of mild cough with scanty mucoid sputum and mild dyspnoea on exertion, which, three months before presentation, had increased rapidly to distress at the slightest movement. He had no fever or weight loss. He had been taking INH, rifampicin, and

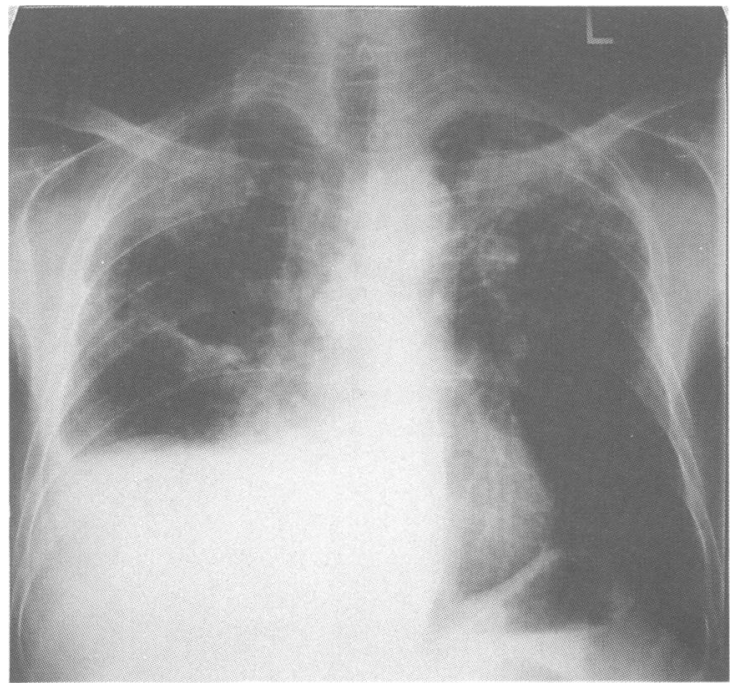

Figure 1 Chest $x$ ray film showing right subpulmonic pleural effusion and massive pulmonary fibrosis.

Medical Department, College of Medicine, King Saud University, Riyadh, Saudi Arabia F A Al-Kassimi pyrazinamide in therapeutic doses regularly for three years, as prescribed in another hospital for clinical suspicion of tuberculosis. He gave a history of heavy exposure to dust most of his life while working as a well digger. On examination he had signs of pleural effusion on the right side. Chest $x$ ray film (fig 1 ) showed, as well as right subpulmonic pleural effusion confirmed by decubitus films (fig 2), bilateral interstitial shadowing more pronounced in the upper zones with massive pulmonary fibrosis. Arterial blood gases were normal at rest. A Mantoux test (using 10 units tuberculin) was negative on two occasions. Sputum cultures, made on six occasions, were negative for mycobacteria and fungi and were free of asbestos bodies. Fibreoptic bronchoscopy showed generalised hyperaemia and oedema of the bronchial mucosa. Bronchoalveolar lavage was negative for mycobacteria and fungi by smear and culture, and a search for asbestos bodies was negative. Transbronchial biopsy of the lung showed infiltration of the interstitial tissues with macrophages and mononuclear inflammatory cells intermixed with carbon particles. There were no ferruginous bodies in several cuts. Birefringent particles (fig 3) compatible with silicosis were seen by polarised light. Pleural aspiration produced

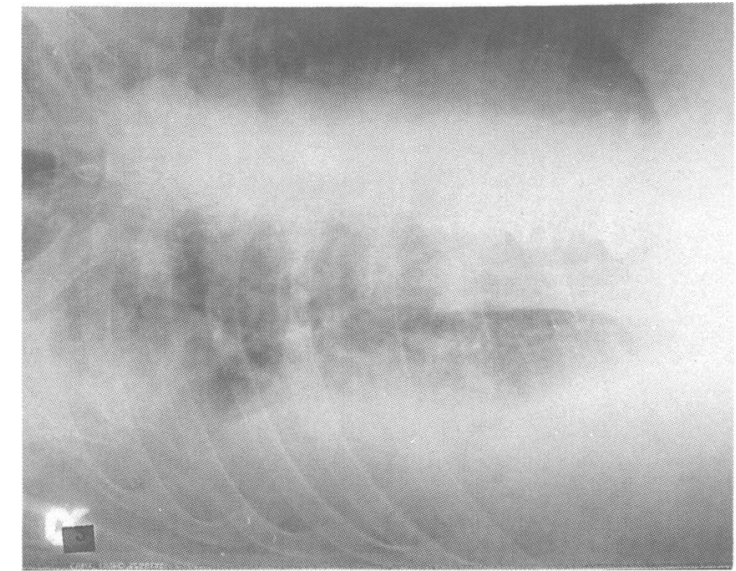

Figure 2 Decubitus film confirming subpulmonic pleural effusion. 


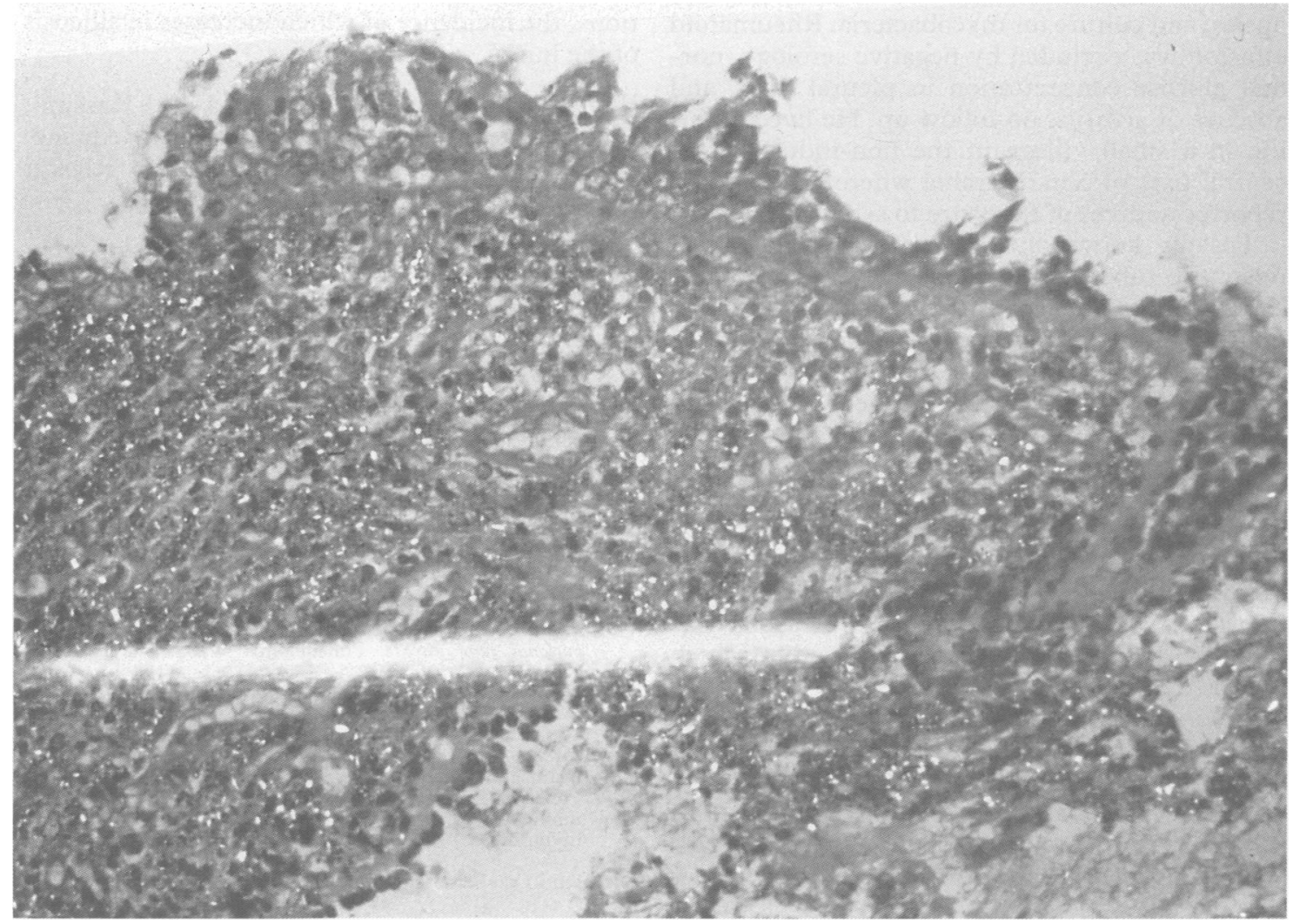

Figure 3 Birefringent particles compatible with silicosis, as seen by polarised light

$500 \mathrm{ml}$ of fluid. The pleural fluid was clear, dark yellow in colour, and was an exudate with high protein and lactate dehydrogenase, normal glucose concentration $(4 \mathrm{mmol} / \mathrm{l})$, and white blood cell count $\left(210 / \mathrm{mm}^{3}, 100 \%\right.$ lymphocytes). Cytology for malignant cells and culture for bacteria, anaerobes, mycobacteria, and fungi were negative. Pleural biopsy showed hyperplasia of mesothelial cells as the only abnormality. The patient was sent home but fluid aspiration and pleural biopsy were repeated three times in the span of six months, with negative results. Pleuroscopy with a rigid bronchoscope showed thickening of pleura with no tubercules or deposits. Multiple biopsies of the visceral pleura were histologically similar to those obtained by Abrams needle. A diagnosis of lung silicosis was made. Chemical pleurodesis, with $1 \mathrm{~g}$ of tetracycline injected intrapleurally, was performed eight months after presentation with appreciable improvement of dyspnoea. Follow up for three and a half years showed no recurrence of the effusion. The pulmonary infiltrate remained unchanged.
Antinuclear factor and rheumatoid factor remained negative, with no clinical evidence of arthritis. A repeat of the Mantoux test two months after presentation also gave negative results.

\section{Discussion}

The patient fulfilled all criteria for diagnosis of silicosis of the lung - namely, (1) history of heavy occupational exposure; (2) chest $x$ ray film showing bilateral symmetrical interstitial infiltrate; (3) negative cultures of sputum and bronchoalveolar lavage for mycobacteria and fungi ${ }^{6-9}$. Also, the histopathology and examination by polarised light of transbronchial biopsies were compatible with silicosis. ${ }^{10}$

A thorough search for an alternative aetiology for the pleural effusion remained consistently negative. Acute causes like pneumonia or pulmonary infarction are unlikely given the chronic nature of the pleural effusion and normal arterial blood gases. Tuberculosis was excluded by failure to respond to $\mathrm{INH}$, rifampicin, pyrazinamide and a repeatedly negative Mantoux test, pleural bi- 
opsies, and culture for mycobacteria. Rheumatoid effusion was excluded by negative serology, normal glucose concentration in pleural fluid, and absence of arthritis on follow up. He lived all his life in a small village in the non-industrialised central part of Saudi Arabia where there are no reported sources of exposure to asbestos.

To our knowledge, pleural effusion (unless related to tuberculosis, a known complication of exposure to silica) is not a recognised manifestation of silicosis of the lung. I speculate that the effusion in the patient was probably linked to silicosis. Extensive adhesions between visceral and parietal pleura (without pleural effusion) are frequently present in postmortem studies of advanced silicosis of the lung. ${ }^{10}$ Although the pleural adhesions might be the sequaelae of healed pulmonary infections like tuberculosis, it is plausible that silicosis could cause a pleural reaction similar to that which occurs in asbestosis. Such a view is supported by animal studies, which found that silica and asbestos fibres share a common inflammatory mechanism ${ }^{3}$ and have identical abilities to release chemical mediators of inflammation ${ }^{4}$ and induce inflammatory serum exudation. ${ }^{5}$ The absence of previous reports of association might be explained by clinicians attributing pleural effusion to pulmonary infec- tions, the incidence of which increases in silicosis of the lung. ${ }^{6}$

Requests for reprints to: Dr F Al-Kassimi, Medical Department (38), College of Medicine, King Saud University, PO Box 2925, Riyadh 11461, Saudi Arabia.

1 Eisenstadt HB. Asbestos pleurisy. Dis Chest 1964;64:78-81.

2 Robinson BWS, Musk AW. Benign asbestos pleural effusion: diagnosis and course. Thorax 1981;36:896-900.

3 Dubois CM, Bissonnette E, Rola-Pleszcynski M. Asbestos fibres and silica particles stimulate rat alveolar macrophages to release tumour necrosis factor-Autoregulatory role of leukotriene B4. Am Rev Respir Dis 1989;139:1257-64.

4 Rom WN, Bitterman PB, Rennard SI, Cantin A, Crystal RG. Characterization of the lower respiratory tract inflammation of nonsmoking individuals with interstitial lung disease associated with chronic inhalation of inorganic dust. $\mathrm{Am} \mathrm{Rev}$ Respir Dis 1987;136:1429-34.

5 Le-Maho S, Bignon J, Lambre C, Jaurand MC, Masse R. Early cellular and biochemical alveolar responses following intracheal inoculation with low dose of asbestos and quartz. Arch Immunol Ther Exp (Warsz) 1984;32:85-98.

6 Ziskind M, Jones RN, Weill H. Silicosis-State of the art. Am Rev Respir Dis 1976;113:643-65.

7 Seaton A. Silicosis. In: Morgan WKC, Seaton A (eds). Occupational lung disease. Philadelphia: WB Saunders, 1984: 266-77.

8 Weill H, Jones RN. Occupational pulmonary diseases. In: Fishman AP. Pulmonary diseases and disorders. New York: McGraw-Hill, 1988;1:828-34.

9 Weill H, Jones RN. Occupational pulmonary diseases. In: Fishman AP (eds). Pulmonary diseases and disorders. New York: McGraw-Hill, 1988;1:833.

10 Dunnill MS. Pulmonary pathology. Edinburgh: Churchill Livingstone, 1982:399-438.

Accepted 7 October 1991 